\title{
Contraception in wildlife
}

\author{
Amanda R Pickard, William V Holt
}

\section{Overview}

The application of reproductive technologies to wildlife has mostly been concentrated on the conservation of endangered species, and has grown in popularity over the last 15-20 years. Studies of the comparative anatomy and physiology of rare or exotic species are no longer undertaken to satisfy the curiosity of philanthropic researchers but through necessity, in attempts to reverse or at least reduce the rate of decline of some species in their natural habitat. Zoos, universities and research institutes play a vital role in carrying out this research worldwide, but much of the technology is developed primarily for medical or agricultural use in the first instance, as funding constraints and limited resources restrict the development of new techniques in the species to which they are ultimately applied. So, what place does contraception have in the conservation of endangered species? This review aims to summarise why limiting breeding can be just as vital to the conservation effort as promoting it. We propose to address the theoretical application of contraception in wildlife and provide examples of how it has been used in practice.

\section{Why do we need to use contraception in wildlife?}

The use of contraception in the context of endangered species might appear at first to be counterintuitive. After all, when the number of individuals in a species is declining, what purpose does restricting reproduction have? Unlike the biomedical researcher, who might prefer to conduct experiments on inbred strains of rats or mice for example, in an effort to minimise erroneous results brought about by inter-individual variability, the major goal of the wildlife biologist is the preservation of genetic diversity, to ensure that the remaining individuals have the best chance of adapting to changes in their environment. It is this ability to adapt that ultimately results in evolution through the survival of the fittest. Nevertheless, in reality the maintenance of genetic diversity is restricted by circumstances such as habitat loss and fragmentation, which prevent the free flow of genetic material within and between subpopulations of endangered species. Within isolated populations breeding may be dominated by one or a small number of individuals, which has the effect of reducing the gene pool yet further. This is particularly relevant for those animals housed in zoos and wildlife parks, which are also taken into account when considering the size of a species' gene pool and need even greater management to minimise the risk of inbreeding.

J Fam Plann Reprod Health Care 2007; 33(1): 48-52 (Accepted 30 October 2006)

Frozen Embryo and Sperm Archive, Medical Research Council, Harwell, Didcot, UK

Amanda R Pickard, BSc, PhD, Deputy Manager

Institute of Zoology, Zoological Society of London, London, UK

William V Holt, MIBiol, PhD, Reader

Correspondence to: Dr Amanda R Pickard, Frozen Embryo and Sperm Archive, Medical Research Council, Harwell, Didcot, Oxfordshire OX11 ORD, UK. E-mail: A.Pickard@har.mrc.ac.uk
Contraception of wildlife has, therefore, been used to limit breeding of animals in captivity. However, this approach has also been taken to limit the proliferation of non-native or introduced species which out-compete the native species within their natural habitat, either by preying on them, by using their available resources, such as food, more efficiently, or by the spread of diseases to which the native species have no resistance. This has been particularly relevant in Australia and New Zealand, where the introduction of species such as the red fox, feral cat, dog, goat and rabbit, at the time of their colonisation by Europeans has had a devastating effect on the native fauna. ${ }^{1}$ Up to 27 species of marsupial are presumed to have become extinct in Australia since the introduction of these alien species, ${ }^{2}$ and many more are either vulnerable to, or threatened with, extinction in their native habitat. Thus, the concept of controlling the spread and vigour of the introduced species is very attractive. Furthermore, in these fragile ecosystems the decline of some native species has promoted the proliferation of others (for example, some species of kangaroo) to the extent that they are now deemed to be pests and adversely affect human interests such as farming. Population control of these pest species is also considered as a way of protecting the environment and those less robust species living in it. Similarly, in the UK this scenario might apply to the relationship between native red squirrels (Sciurus vulgaris) and their introduced competitor, the grey squirrel (Sciurus carolinensis) Since their introduction at the turn of the 20th century, grey squirrels have decimated red squirrel populations through competition for food resources and by the spread of parapox virus, to which red squirrels are particularly susceptible. Mass culls of non-native and pest species might be an effective means of control, but are not usually an option due to animal welfare considerations.

\section{Strategies for contraception}

There are a number of alternative strategies for using contraception in wildlife. The method chosen will largely depend on the technology and resources available at the time. However, consideration should also be given to the effect that contraception may have on the behaviour and social status of the targeted individual(s).

\section{Separating male and female animals}

In captivity, breeding can be prevented by housing mature males and females in separate enclosures, but it is now known that animals which naturally live in social groups may suffer greatly if this social structure is not replicated in their captive environment. No longer is it considered acceptable for zoos to simply house a male-female pair for the purpose of exhibiting a diverse range of species to the public. Now, great efforts are made to reproduce the natural social situation wherever possible, and collections that do not have the space or resources to do so are inclined to move their specimens to those that do.

Manipulating the breeding of dominant individuals Some species such as the Dama gazelle (Gazella dama) and Hanuman langur (Semnopithecus entellus) live in single-male, multi-female social groups or harems. The 
dominant male therefore fathers all of the offspring in that group, until such time as a subordinate male succeeds in overthrowing him and taking his place. Conversely, in other species such as the grey wolf (Canis lupus) the dominant or alpha female may dominate the breeding in the pack. Preventing the dominant individual(s) from breeding in either of these social situations may have serious consequences for their status in the group and may result in their being rejected or even killed by other group members. Furthermore, restricting the breeding of dominant individuals may result in the promotion of breeding in subordinate members of the group, thus having the opposite to the desired effect of reducing the number of individuals born. Careful consideration of behavioural ecology should therefore be taken before embarking on a contraception programme.

\section{Surgical sterilisation}

Surgical sterilisation has limited practical application in the contraception of wildlife, but may be used in some zoos or other captive situations where a specific individual maybe over-represented in the gene pool. One advantage of surgical contraception is that it can usually be carried out without affecting that individual's social position, as the endocrine axis that drives behaviour remains intact, at least in the short- to mid-term. However, the anaesthesia required to perform the surgery is not without risk and surgical sterilisation should be considered permanent. Whilst permanent sterilisation might be a desirable end point for limiting non-native or pest species in the wild, in captivity this is less desirable particularly if the objective is to prevent an individual from breeding for a temporary period, for example if they are waiting to be transported to a new facility and unrelated mates.

Pharmaceutical or immunological contraception provide greater opportunities for use in captive wildlife as there is more chance that they are temporary or reversible. The challenge here is to find a suitable method for delivering the contraceptive agent to the targeted individuals or population.

\section{Endocrine-based contraception}

The endocrine system has been successfully perturbed in wildlife control. ${ }^{3}$ Releasing hormone agonists, which act centrally to depress all reproductive activity, and steroid hormones, which act peripherally at the level of the gonad, have both been used to disrupt reproduction. However, negative effects on behaviour, as described above, may be unwanted side effects. Most contraceptives that target the endocrine system are drug-based and a specific dose of the agent must be delivered for them to be effective. On a small scale, in captivity for example, oral delivery may be an option, although in many situations it is impossible to establish that the specified dose has been received by the targeted individual(s) on a regular basis. Failure to maintain the appropriate level of contraceptive agent in the system will result in a return of reproductive activity. One alternative approach is the use of silastic implants to deliver the contraceptive agents over a sustained period of time. In captivity these have the advantage of delivering the contraceptive agent directly to the target individual(s), and they can be replaced at intervals to maintain their level of cover. However, they can become dislodged and an unexpected return to fertility may occur.

Endocrine-based contraception was previously the method of choice for wildlife as it has been relatively easy to apply principles established in human medicine. The gonadotrophins are simple peptides that demonstrate a high degree of conservation across species, and the steroid hormones are ubiquitous, having a similar mode of action in all species. However, as a result, targeting the endocrine system for contraception in free-living wildlife is rather non-specific and can potentially result in the contraceptive agents being delivered to non-target individuals. To avoid this undesirable outcome the mode of delivery must be designed in such a way that it is specific to the species of interest. For example, it may be possible to develop baited food of an appropriate colour or size, such that it is preferentially taken up by the target species, or to deliver the bait in such a way that the non-target species are unlikely to come into contact with it. This approach might be feasible on an island, where there are strict boundaries to the area across which species must be managed and also a restricted number of species in the vicinity, but in reality ensuring the contraception is delivered to one species and not others is almost impossible to achieve using this approach.

Live vector systems are being explored as a means of effectively delivering contraception at the ecological level.4,5 In this scenario the contraceptive agent is engineered into a live virus, which then spreads 'naturally' through the target population. Using this approach, species specificity is much more practical to achieve. Nevertheless, the risk of a virus mutating and either rendering itself ineffective at delivering the contraceptive, or worse becoming capable of infecting a broad range of species, should still be taken into account. Further to this, the ethics of releasing genetically modified organisms into the environment are still being debated. Therefore, while the technology necessary to apply vector delivery contraceptives is being developed in the laboratory, it has yet to be tested in earnest in a field situation.

\section{Immunocontraception}

One of the most attractive options for contraception in wildlife is the prospect of using an individual's immune system to prevent fertilisation or embryo development. In practice, egg and sperm antigens have been targeted most frequently, but in theory immunological disruption of embryo implantation would also be effective. Whole porcine zona pellucida was the first immunological contraceptive used in wildlife 6 and has been used effectively in a broad range of species both in the wild and in captivity. However, the vaccine is usually delivered by darting and two doses are required to produce an effective level of immunity. Furthermore, the lack of species specificity means that the issues of how to deliver the vaccine and prevent it causing contraception in non-target species, which were considered for endocrine agents, need to also be taken into account.

As the zona pellucida matrix consists of three major glycoproteins (ZP1, ZP2 and ZP3) it has been relatively easy to characterise and determine the role of the different components. 7 ZP3 has been found to be expressed in growing oocytes and to be responsible for initial sperm-egg binding. 5 This glycoprotein, which is also immunogenic, has been targeted as a potential candidate for immunocontraceptive development, and antibodies against ZP3 have successfully caused infertility in a number of species. ${ }^{8}$ The $\mathrm{ZP}$ antigens produce their contraceptive effects either by preventing the interaction of the sperm and egg at fertilisation or by the stimulation of cytotoxic T-cells which destroy the developing ovarian follicles. Such permanent ovarian pathology might be acceptable when attempting to control pest species, but is less desirable where reversible contraception is the objective. Therefore, further work is required to identify 
the specific epitopes that play a role in fertilisation and also preferably afford some degree of species specificity at the same time. 5

It is well known that anti-sperm antigens can naturally cause infertility, and immunisation with whole sperm preparations was used to induce infertility in several mammalian species as early as $1966.9^{9}$ However, identifying suitable immunologically active proteins on the sperm surface, which is an extremely complex structure, has not been straightforward. To be effective the target protein must be exclusively expressed in the male reproductive tract and play a role in sperm function or cause agglutination of the sperm thus preventing them from fertilising the oocyte. While several candidate proteins have been identified, success so far using this approach has been relatively limited. 5

\section{End points for contraception programmes}

Before embarking on a strategy of contraception it is important to consider the desired end points for the programme to be effective. In captivity these may be relatively obvious: temporary or permanent cessation of breeding of an individual or group of individuals. However, it is important to consider the effect that this action might have on inbreeding coefficients and population viability overall. Studbooks are used to record, manage and analyse births, deaths and the relatedness of individuals of a species in captivity, and make informed decisions about future breeding priorities. Usually the decision to use contraception will have been taken in conjunction with the studbook keepers, but collections that may be struggling to keep their population within their carrying capacity could make an autonomous decision to stop or delay breeding, which might unexpectedly increase the homozygosity of deleterious alleles in the population as a whole.

Where contraception is being considered as a strategy for managing pest species in the field, additional issues need to be taken into consideration. In this scenario, to be effective birth rates must be reduced to such a level that at most they match the minimum density-independent death rate. ${ }^{10}$ Achieving this goal can depend on the nature of the contraceptive delivery system used. For example, if a non-disseminating delivery system is used (such as baiting or darting) where there is no spread of contraceptive effect from one individual to another, a greater proportion of the population may need to be targeted than initially anticipated to account for any unexpected increase in recruitment of young into the breeding population and/or immigration of breeding individuals from neighbouring populations. However, if a transmissible, disseminating vector such as a genetically modified virus is to be used, fewer individuals may need to be contracepted as a reduction in pregnancy rate may in turn result in an increase in mating attempts therefore increasing contact between individuals and the prospects of the virus being transmitted throughout the population. Field trials are a valuable tool for producing information that can be modelled when planning the most appropriate method for a contraception programme.

\section{Practical case studies}

Some relatively high-profile attempts at developing contraceptives for wildlife management have been documented in the literature. Other, more technical approaches are still being researched and therefore relatively less well known. Examples of both are given here.

\section{Pregnancy termination in feral cats using a prolactin} inhibitor, cabergoline

Jöchle and Jöchle ${ }^{11}$ reported success in controlling North American feral cat populations by lacing the food of pregnant queens with the prolactin inhibitor, cabergoline. Prolactin inhibitors are known to interrupt pregnancy in both dogs and cats if administered during the second half of gestation, ${ }^{12,13}$ and despite repeated use of the active substance resulting in effective termination of successive pregnancies, queens were capable of subsequently carrying a pregnancy to term and producing normal healthy offspring. ${ }^{11}$ Whilst this approach satisfies the need for reversible contraception, it is relatively labour-intensive and the risk of the active agent being taken up by non-target individuals is unacceptably high for it to be used on a large scale. Furthermore, many members of the public would consider the prevention of conception a far more acceptable strategy for controlling populations than the termination of pregnancy.

\section{Suppression of spermatogenesis in dogs}

Stray dogs, like feral cats, present problems in urban areas as they act as reservoirs of disease for domestic pets and can threaten native wildlife in locations where they would not normally be resident. Based on evidence that injections of medroxyprogesterone acetate (MPA) administered in conjunction with testosterone resulted in temporary azoospermia in humans, ${ }^{14}$ Paramo et al. ${ }^{15}$ investigated the effects of MPA on male dogs. Although fortnightly or monthly injections of MPA failed to induce azoospermia in the dog, significant changes in sperm morphology (in particular in acrosome integrity) were observed, suggesting that fertility would be reduced. In the same study, gonadotropin-releasing hormone $(\mathrm{GnRH})$ agonist administration resulted in a cessation of normal spermatogenesis and histological changes in the epididymides. Eventually ejaculate volume decreased. ${ }^{15}$ This work once again demonstrates proof-in-principle that some of the basic knowledge of contraceptives in humans can be extended to non-human mammals. However, there is a significant amount of research and development necessary for these small-scale observations to be translated into a practical, field-orientated programme.

\section{GnRH analogues for contraception in both sexes}

More recently, the GnRH analogue, deslorelin, has been used to down-regulate fertility in both males and females of a variety of exotic species. Originally developed in Australia as an ovulation-inducing agent in mares, ${ }^{16}$ this compound has subsequently been used to suppress reproduction in domestic cats and dogs, ${ }^{17,18}$ and since the production of a long-acting subcutaneous deslorelin implant, has been evaluated for use in several wild species. Bertschinger et al. ${ }^{19}$ recently reported that annual implants of $6 \mathrm{mg}$ deslorelin into male cheetahs (Acinonyx jubatus) successfully suppressed spermatogenesis for up to 5 years. Similarly, in a preliminary study of two females, reproductive activity in giraffes (Giraffa camelopardalis) was suppressed for more than 12 months following a single subcutaneous deslorelin implant. ${ }^{20}$ Deslorelin has also been shown to be effective in contracepting both male and female Tammar wallabies (Macropus eugenii), ${ }^{21,22}$ further demonstrating the broad applicability of this compound.

Clearly, deslorelin has significant potential for further development as a broad application contraceptive compound. The fact that long-acting implants are already available and have as yet been shown to have little or no detrimental side effects in a variety of species also suggests that this compound will continue to be of interest to 
researchers and wildlife managers. Nevertheless, the challenges of effectively delivering the compound to a target species or individual still need to be addressed before a reliable, cost-effective application for this compound can be determined.

\section{Immunocontraception in African elephants}

One of the most high profile uses of contraception in the field has been the use of porcine zona pellucida vaccines to control the fertility of free-living African elephant (Loxodonta africana) populations. ${ }^{23}$ Elephants are largely confined to protected game reserves in their natural range. These reserves have a finite capacity, and when this is exceeded those animals that cannot be accommodated stray out into the neighbouring areas and usually come into conflict with the local people using the land for agriculture, and/or become victims of poachers as they are relatively unprotected. Developing a method for controlling elephant populations is therefore highly attractive. The ideal contraceptive would be long acting and yet reversible, as this species is highly social and younger females need to learn appropriate reproductive behaviours from older females in order to successfully raise their own offspring.

Trials of porcine zona pellucida vaccine demonstrated that a primary vaccination followed by two booster vaccinations at 4 weeks and 10 months resulted in significant serum antibody titres for between 12 and 14 months after the third dose. The charismatic nature of these animals means that many are known individually to game wardens or scientists observing their welfare on a regular basis, thus making the prospect of delivering vaccines to individuals by dart feasible. However, postmortem studies have shown that some females suffer from irreversible ovarian pathology, and therefore a more refined vaccine would be preferable.

\section{Pest control of brushtail possums in New Zealand} Brushtail possums (Trichosurus vulpecula) were introduced from Australia to New Zealand about 150 years ago to develop a fur trade. However, populations have expanded to pest proportions, causing a widespread destruction of New Zealand's native plants. A speciesspecific method of controlling possum populations that can be remotely delivered is desirable, and has been the focus of a significant amount of research in Australia and New Zealand in recent years. While attempts are made to develop a suitable vaccine for possum control, field- and pen-based studies have been undertaken to determine end points which must be achieved for a contraceptive programme to be effective.

Using surgical sterilisation (castration, ovariectomy or tubal ligation) of free-living possums, it has been possible to investigate the proportion of a possum population that needs to be prevented from breeding to bring population growth under control. In situations where more than 50\% of the breeding females in a population were sterilised by tubal ligation, recruitment of young was significantly reduced to produce negative population growth. However, immigration of fertile females from neighbouring populations had the potential to override the effects of fertility control. When the proportion of females sterilised by tubal ligation was increased to $80 \%$ the prevalence of the possum-specific bacterium, Leptospira interrogans serovar balcanica, increased, this probably being due to increased social contact brought about by an increase in frequency of mating behaviour. It could therefore be concluded that fertility control that permits the maintenance of reproductive behaviour might be used to facilitate the transmission of vectors used to disseminate the contraceptive agent. Meanwhile, when sterility was afforded by castration or ovariectomy (thus preventing reproductive encounters), possum behaviour was altered to an extent that the efficacy of a vector dissemination system would be significantly affected. ${ }^{10}$

\section{Alternative methods of population control}

Potential alternatives to contraception are worthy of consideration for the control of populations of wild animals. For example, it has been discovered that species introduced from Europe to Australia are susceptible to a plant toxin, sodium monofluoroacetate (also known as Compound 1080), which is found in high concentrations in native pea plants (Gastrolobium spp.) in Western Australia. Native animals have co-evolved with these plants and have developed resistance to their toxic effects. ${ }^{2}$ Therefore, by strategic use of pea plant thickets it has been possible to selectively control introduced fox and cat populations, and insure the survival of some native species that would otherwise be subjected to over-predation. While it is unlikely that opportunities such as this will present themselves frequently in nature, a detailed understanding of habitat use by different species might provide information that can be used to control wild populations that would otherwise need to be managed by traditional methods such as shooting or trapping. Increasingly these methods are found to be unacceptable by the general public.

\section{Conclusions}

There are many different approaches that can be taken to control reproduction in wildlife. The strategy chosen depends on a number of variables including social issues, ecological issues, the extent to which reproduction needs to be curtailed, and limitations of delivering the contraception to the target species. As is so often the case, wildlife biologists benefit from human reproductive research by being able to modify and adapt techniques that have proved successful in medicine. However, in the development of contraceptives for wildlife there are a number of issues that would not be considered relevant to humans and which need to be taken into account. Therefore, specific programmes of research and development are essential to ensure continued progress in this field.

It is now recognised that due to the actions of man there are no longer any truly 'wild' species as natural habitats are continually shrinking and becoming fragmented. Therefore, even species in their natural environment require a degree of management to ensure that the delicate balance of nature does not tilt too far in favour of some species at the expense of others.

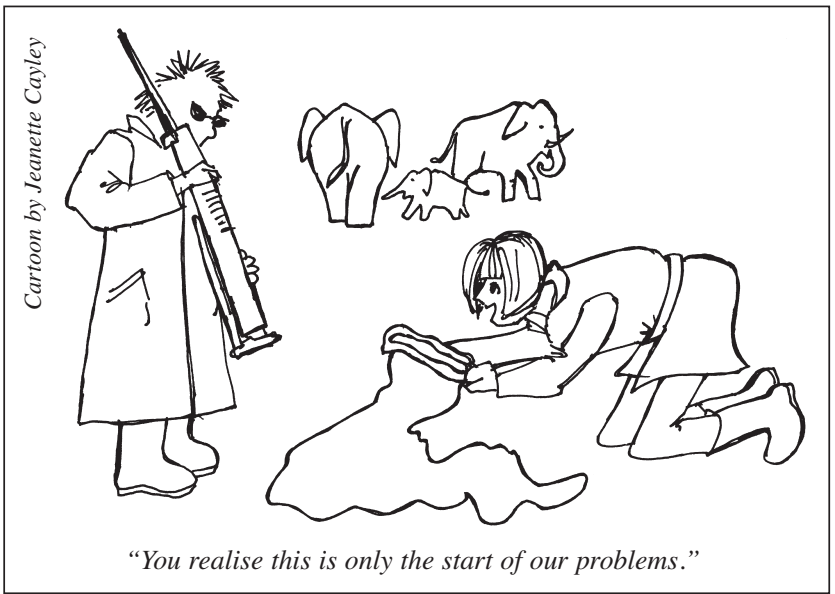


Statements on funding and competing interests Funding None identified.

Competing interests None identified.

\section{References}

1 Temple-Smith PD. Integrating reproductive sciences into recovery programmes for declining and extinct marsupial populations. In: Holt WV, Pickard AR, Rodger JC, Wildt DE (eds), Reproductive Science and Integrated Conservation. Cambridge, UK: Cambridge University Press, 2003; 211-231.

2 Fletcher T, Morris K. Captive breeding and predator control: a successful strategy for conservation in Western Australia. In: Holt WV, Pickard AR, Rodger JC, Wildt DE (eds), Reproductive Science and Integrated Conservation. Cambridge, UK: Cambridge University Press, 2003; 232-248.

3 Bomford M. A Role for Fertility Control in Wildlife Management? (Bulletin No. 7). Canberra, Canada: Bureau of Rural Resources, 1990

4 Rodger JC. Fertility control for wildlife. In: Holt WV, Pickard AR, Rodger JC, Wildt DE (eds), Reproductive Science and Integrated Conservation. Cambridge, UK: Cambridge University Press, 2003; 281-290.

5 Mate KE, Hinds LA. Contraceptive vaccine development. In: Holt WV, Pickard AR, Rodger JC, Wildt DE (eds), Reproductive Science and Integrated Conservation. Cambridge, UK: Cambridge University Press, 2003; 291-304.

6 Kirkpatrick JF, Liu IKM, Turner JW Jr, Naugle R, Keiper RR Long-term effects of porcine zonae pellucidae immunocontraception on ovarian function of feral horses. J Reprod Fertil 1992; 94: 437-444.

7 Epifano O, Dean J. Biology and structure of the zona pellucida: a target for immunocontraception. Reprod Fertil Dev 1994; 6: 319-330.

8 Prasad SV, Wilkins B, Dunbar BS. Molecular biology approaches to evaluate species variation in immunogenicity and antigenicity of zona pellucida proteins. J Reprod Fertil Supp/ 1996; 50: 143-149.

9 Mclaren A. Studies on the immunisation of mice with spermatozoa. Fertil Steril 1966; 17: 492-497.

10 Cowan P, Pech R, Curtis P. Field applications of fertility control for wildlife management. In: Holt WV, Pickard AR, Rodger JC, Wildt DE (eds), Reproductive Science and Integrated Conservation. Cambridge, UK: Cambridge University Press, 2003; 305-318.

11 Jöchle W, Jöchle M. Reproduction in a feral cat population and its control with a prolactin inhibitor, cabergoline. J Reprod Fertil Supp/ 1993; 47: 419-424.
12 Jöchle W, Arbeiter K, Post K, Ballabio R, D'Ver AS. Effects on pseudopregnancy, pregnancy and interoestrous intervals of pharmacological suppression of prolactin secretion in female dogs and cats. J Reprod Ferti Supp/ 1989; 39: 199-207.

13 Vickery BH, McRae GI, Goodpasture JC, Sanders LM. Use of potent LHRH analogues for chronic contraception and pregnancy termination in dogs. J Reprod Fertil Supp/ 1989; 39: 175-187.

$14 \mathrm{Wu}$ FCW. Suppression of sperm function by depot medroxyprogesterone acetate and testosterone enanthate in steroid male contraception. Fertil Steril 1989; 51: 691-698.

15 Paramo RM, Renton JP, Ferguson JM, Concannon PW. Effects of medroxyprogesterone acetate or gonadotrophin-releasing hormone agonist on suppression of spermatogenesis in the dog. J Reprod Fertil Suppl 1993; 47: 387-397.

16 Meyers PJ, Bowman T, Blodgett G, Conboy HS, Gimenez T, Reid MP, et al. Use of the GnRH analogue, deslorelin acetate, in a slow-release implant to accelerate ovulation in oestrous mares. Vet Rec 1997; 140: 249-252.

17 Munson L, Bauman JE, Asa CS, Jöchle W, Trigg TE. Efficacy of the $\mathrm{GnRH}$ analogue deslorelin for suppression of oestrous cycles in cats. J Reprod Fertil Supp/ 2001; 57: 269-273.

18 Trigg TE, Wright PJ, Armour AF, Williamson PE, Junaidi A, Martin GB, et al. Use of a $\mathrm{GnRH}$ analogue implant to produce reversible long-term suppression of reproductive function of male and female dogs. J Reprod Fertil Suppl 2001; 57: 255-261.

19 Bertschinger HJ, Jago M, Nöthling JO, Human A. Repeated use of the $\mathrm{GnRH}$ analogue deslorelin to down-regulate reproduction in male cheetahs (Acinonyx jubatus). Theriogenology 2006; 66: 1762-1767.

20 Patton ML, Bashaw MJ, del Castillo SM, Jochle W, Lamberski $\mathrm{N}$, Rieches R, et al. Long-term suppression of fertility in female giraffe using the $\mathrm{GnRH}$ agonist deslorelin as a long-acting implant. Theriogenology 2006; 66: 431-438.

21 Herbert CA, Trigg TE, Renfree MB, Shaw G, Eckery DC, Cooper DW. Effects of a gonadotropin-releasing hormone agonist implant on reproduction in a male marsupial, Macropus eugenii. Biol Reprod 2004; 70: 1836-1842.

22 Herbert CA, Trigg TE, Renfree MB, Shaw G, Eckery DC, Cooper DW. Long-term effects of deslorelin implants on reproduction in the female tammar wallaby (Macropus eugenii). Reproduction 2005; 129: 361-369.

23 Fayrer-Hosken RA, Bertschinger HJ, Kirkpatrick JF, Grobler D, Lamberski N, Honneyman G, et al. Contraceptive potential of the porcine zona pellucida vaccine in the African elephant (Loxodonta africana). Theriogenology 1999; 52: 835-846

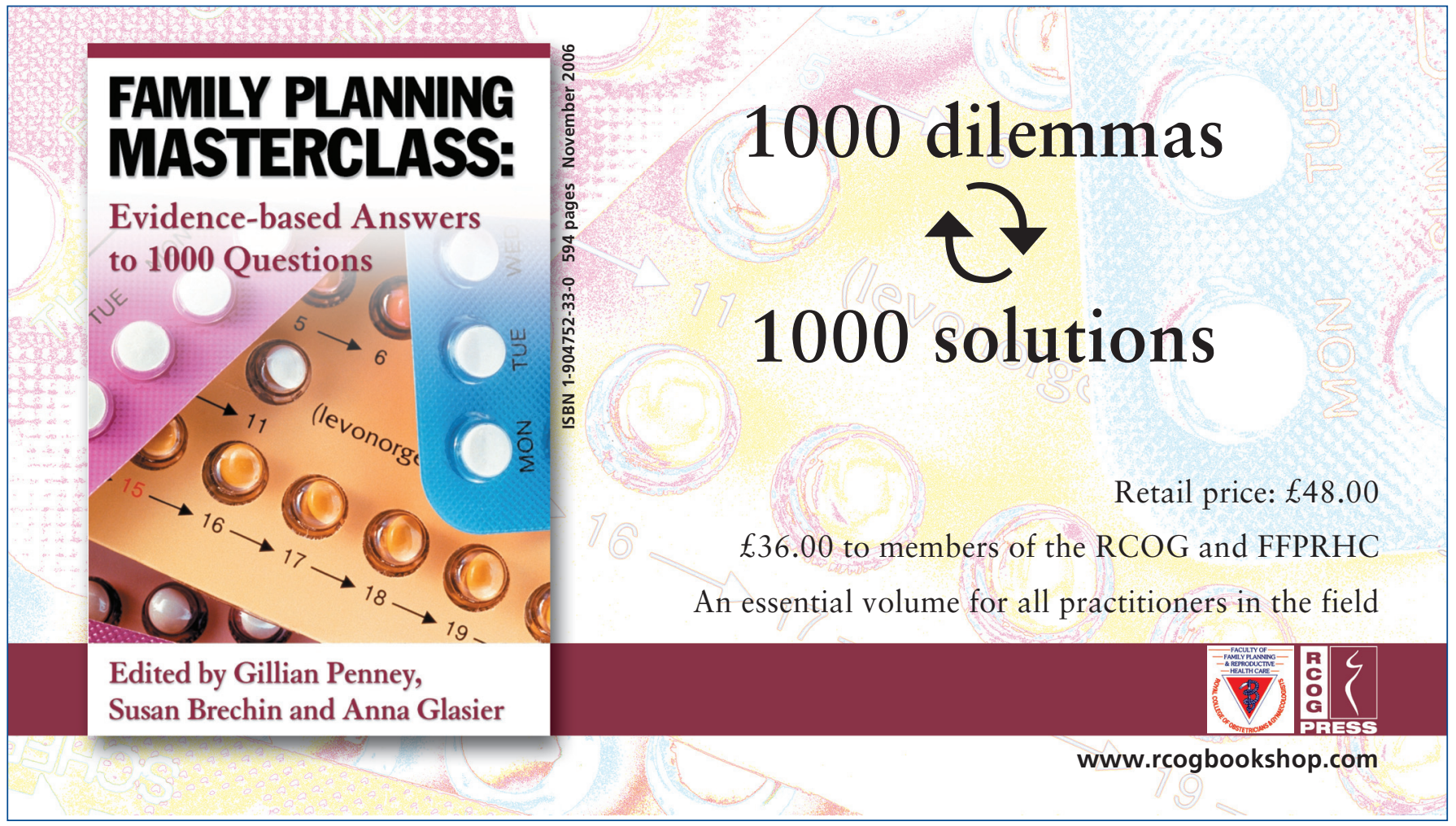

